\title{
2 Differential diagnosis of vertebral spinous process deviations in archaeological and modern domestic dogs
}

4 Dennis F. Lawler, ${ }^{\mathrm{a} e,}{ }^{*}$, Christopher C. Widga ${ }^{\mathrm{a}}$, David A. Rubin ${ }^{\mathrm{b}}$, Jennifer A. Reetz ${ }^{\mathrm{c}}$, Richard H.

$5 \quad$ Evans $^{\mathrm{e}}$, Basil P. Tangredi ${ }^{\mathrm{f}}$, Richard M. Thomas ${ }^{\mathrm{g}}$, Terrence Martin ${ }^{\mathrm{a}}$, Charles Hildebolt ${ }^{\mathrm{b}}$, Kirk

$6 \quad$ Smith $^{\mathrm{b}}$, Daniel Leib ${ }^{\mathrm{d}}$, Jill E. Sackman ${ }^{\mathrm{h}}$, James G. Avery, Gail K. Smith ${ }^{\mathrm{c}}$

$7{ }^{a}$ Illinois State Museum, Research and Collections Center, 1011 East Ash St., Springfield, IL

8 62703-3500, USA

$9 \quad{ }^{\mathrm{b}}$ Mallinckrodt Institute of Radiology (Box 8131), Washington University School of Medicine, 10510 S. Kingshighway Blvd, St Louis, MO 63110, USA

$11{ }^{\mathrm{c}}$ Department of Clinical Studies, School of Veterinary Medicine, University of Pennsylvania, 123900 Spruce St., Philadelphia, PA 19104, USA

13 d11506, BJCIH, Washington University in St Louis, MO 63110, USA

$14{ }^{e}$ Pacific Marine Mammal Center, 20612 Laguna Canyon Road, Laguna Beach, CA 92651, USA

$15 \quad{ }^{\mathrm{f}}$ Department of Biology, Green Mountain College, Poultney, VT 05764 USA

16 g School of Archaeology and Ancient History, University of Leicester, University Road,

17 Leicester, UK, LE1 7RH

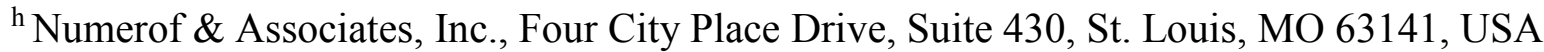

$19{ }^{i}$ Department of Internal Medicine, Washington University School of Medicine, (Grant Medical

20 Clinic, 114 N. Taylor Ave., St. Louis MO 63108, USA)

21

22 Key Words: Archaeology, Dog, Canis lupus familiaris, Micro-computed tomography,

23 Differential diagnosis, Paleopathology, Vertebra

24

$25 *$ Corresponding author:

26 CC Widga; Illinois State Museum Research \& Collections Center; Springfield IL

27 cwidga@museum.state.il.us 


\section{Abstract}

Paleopathological study of domestic animal remains can elucidate human-domesticate relationships, when all reasonable differential diagnoses are considered. Deviated spinous processes found on ancient domesticated dog vertebrae have been assumed to result from pack burdens, although consideration of diagnostic alternatives has been unclear. To more thoroughly assess the potential significance of these features, we first generated an extensive differential diagnosis of potential causes. Broad causal categories included: (i) morphological; (ii) infectious; (iii) taphonomic; (iv) life history (in utero to death), with numerous subcategories that sometimes overlap. We then evaluated these possibilities through an observational and radiology study of 15 ancient deliberate domestic dog burials (191 vertebrae) from the midwestern USA, dating between 10,130 and 200 years ago. Archaeological specimens from the UK were included to evaluate for geographic uniqueness of our observations. We characterized deviations of spinous processes of cervical $(n=74)$, thoracic $(n=51)$, lumbar $(n=60)$, and sacral $(n=6)$ vertebrae.

1 Affected spinous processes were found in 34\% of cervical vertebrae, $63 \%$ of thoracic vertebrae, $278 \%$ of lumbar vertebrae, and $50 \%$ of sacral vertebrae. Four types of spinous process deviations 3 were observed: (a) lateral leaning from the base but not otherwise deviated; (b) lateral curving at 4 some point above the base; (c) bowing because of multiple curves; and (d) torsion along the vertical axis. Computed tomography and micro-computed tomography were essential tools for establishing differential diagnoses. 


\section{Introduction}

Ancient animal bones offer a unique biological record that informs upon the health of animals associated with human cultures, and indirectly addresses relationships between humans and their domesticates (Baker, J.R. Brothwell, 1980; Davies et al., 2005; Bartosiewicz and Gal, 2013). Although there is a long history of paleopathological study in archaeology (Moodie, 1923), advanced imaging technology (Chhem and Brothwell, 2008), an expanding knowledge base, and increasing academic interest (Davies et al., 2005; Miklíková and Thomas, 2008), demand clarified interpretations.

Dogs and humans have maintained a domestic relationship for at least 12,000 years. Although the exact origins of this relationship remain somewhat obscure (Miklosi, 2007; Larson et al., 2012), the close association of dogs and humans in cultural contexts lend special significance to dog evolution and behavior (Morey, 2006, 2010). Paleopathological studies can contribute new understandings of the nature of human-dog relationships through analyses of behaviorallyinfluenced damage to bones and joints, or diseases and injuries sustained through life activities (Snyder, 1995; Tourigny et al., 2015). Dog paleopathology specifically has the potential to inform about subsistence or mobility strategies among human groups (Warren, 2004; Lawler et al., 2015).

Previous paleopathological studies of domestic dogs have focused on opportunistic observations of gross pathologies (Warren, 2004; Walker et al., 2005; Ware, 2006). Only rarely (Tourigny et al., 2015) have such studies incorporated medical imaging (radiology and tomography) or rigorous differential diagnosis, despite example work in human paleopathology (Miller et al., 1996; Ortner, 2003; Lynnerup, 2010) and forensics (Jalalzadeh, H. et al., 2015).

Deviated spinous processes of domestic dog vertebrae have been observed with inter-vertebral osteoarthritis, presumed compression fractures of epiphyseal endplates, and scapular modification (Snyder, 1995; Warren, 2004). However, arguments that deviated spinous processes suggest use as a pack animal were made in the absence of observing associated pathologies (Warren, 2000; Darwent and Gililand, 2001; Walker et al., 2005) or providing for differential diagnosis. Thus, the interpretation became perpetuated in literature when in fact the early diagnoses actually were speculative and in need of further study. 
77 We present a differential diagnosis of deviated vertebral spinous processes in archaeological

78 domestic dogs. We include archaeological dog remains from the midwestern USA and Great

79 Britain for comparative evaluation for geographical uniqueness of our observations, and have

80 used computed tomography and digital radiography in selected instances. Although we narrow

81 the range of diagnostic possibilities, limitations inherent in archaeological materials often

82 preclude definitive diagnosis.

\section{Materials and Methods}

85 Most vertebral remains that are described in this report are curated at the Illinois State Museum

86 Research and Collections Center, Springfield IL USA. The specimens represent both deliberate

87 burials and isolated vertebrae recovered from nine archaeological sites in Illinois and Missouri

88 (Fig. 1) (Fowler, 1959; Griffin and Morse, 1961; Wray and MacNeish, 1961; Parmalee et al.,

89 1972; McMillan, 1976; Morey and Wiant, 1992). These assemblages span the Archaic to late

90 Mississippian periods, from 10,130 - 200 cal BP (Table 1). Vertebrae from a Roman (mid-2 ${ }^{\text {nd }}$ to

91 mid- $3^{\text {rd }}$ century AD) dog recovered from Alchester, Oxfordshire UK, were included to evaluate

92 similar morphologies from a geographically, taphonomically, and temporally distant context.

\section{$94 \quad 2.1 .1$ Biological Factors}

95 Earlier zooarchaeological observations of buried dogs were focused partly on establishing age 96 and sex of individuals. A detailed scheme for aging Canis lupus lupus based on tooth wear

97 (Nowak et al., 2000) was not used because our age categories were too coarse to account for 98 uncertainties of diet and lifestyle influences.

99 We assessed age on a relative scale, considering degree of epiphyseal union of major long bones, 100 along with dental eruption and attrition. Individuals $<2$ years of age were assigned to general age 101 classes based on long bone epiphyseal closure (Newton and Nunamaker, 1985). Age estimates of 102 individuals $>2$ years were assessed primarily based on dental attrition. 
103 Shoulder height, a relative measure of body size, was calculated based on humeral length, using 104 standard linear regression equations (Harcourt, 1974). Burials from the Stilwell and Apple Creek 105 (Burial 3) sites lacked humeri, so shoulder height was calculated using radius and femur, 106 respectively.

107 A baculum (os penis) indicated burial of a male. However, absence of a baculum did not

108 necessarily indicate a female, considering the possibilities of non-preservation, non-recovery, or 109 removal. Thus, burials without a baculum were categorized as female/indeterminate.

110 We did not assess age, sex, or body-size characteristics of disarticulated, isolated specimens, due 111 to the possibility of mixing elements from different individuals.

$112 \quad \underline{2.1 .2}$ Taphonomic Factors

113 A number of post-mortem taphonomic processes can affect bone integrity and appearance 114 (Lyman, 1994; Haglund and Sorg, 1997), causing partial-to-total destruction. Physical examples 115 of these processes include modification by scavenging animals and sub-aerial weathering that 116 often remove osteological materials from the sedimentary record.

117 Chemical changes may alter bone morphology in situ. Low soil pH can completely remove 118 organic materials. In moist-to-saturated depositional contexts, low $\mathrm{pH}$ can affect bone rigidity by 119 promoting decalcification (Brothwell and Gill-Robinson, 2001) and predisposing bones to 120 deformation by sedimentary forces. Carcass decomposition itself promotes a low $\mathrm{pH}$ 121 environment (Gill-King, 1997), and drying creates stress on muscle and ligament attachments 122 (Weigelt, 1989). The result can be minor warping of skeletal elements.

123 To evaluate these taphonomic possibilities, all specimens were examined microscopically (low 124 power magnification) for indicators of a low $\mathrm{pH}$ depositional history that include exterior 125 solution pitting and erosion (Johnson et al., 1997), gastric polish (Andrews, 1990), and root 126 etching (Morlan, 1984). 
129 Spinous processes were recorded as normal or deviated, with the latter categorized into four types: (a) lateral leaning from the base but otherwise not malformed (Fig. 2a); (b) lateral curving at some point above the spinous base (Fig. 2b); (c) bowing because of multiple curves (Fig. 2c); (d) torsion along the longitudinal axis (Fig. 2d). Data were recorded by spinal region, deviation category and direction, and qualitative severity of pathology. All affected vertebrae were photographed and described. Vertebrae were not measured because the large size variability among ancient dogs, just as among modern dogs, precludes useful biological interpretation.

Statistical analyses (Fisher's exact test) were limited to relationships among leaning, lateral curving, and bowing, for frequency, severity, and right-left direction. Statistical analyses included only data from the Illinois sites and Rodgers Shelter MO. Additional statistical evaluations were not conducted because the data are too sparse for further sub-categorization, especially considering that they are non-independent, and that a valid negative control population cannot be identified.

\section{$\underline{2.3 \text { Imaging studies }}$}

Four vertebrae were transported to Washington University School of Medicine (WUSM, St. Louis MO USA) for non-invasive imaging using microcomputed tomography $(\mu \mathrm{CT})$ with a vivaCT 40 (Scanco Medical, Switzerland) instrument, made available through the musculoskeletal structure and strength core at WUSM. These four specimens were selected because visual inspection suggested that different diagnoses would be recognized among them. Imaging parameters for these specimens were $70 \mathrm{kVp}$ and $114 \mathrm{uA}$, voxel size $21 \mathrm{um}^{3}$ with an integration time of 300ms. Four vertebrae were selected deliberately as examples, based on suspicion that scanning would yield different diagnoses.

Computed tomography (CT) images of four adult dogs (University of Pennsylvania School of Veterinary Medicine, Philadelphia PA USA) also were included to describe vertebral spinous process deviations discovered during life, for comparative evaluation of gross morphologies.

\section{Results}




\subsection{Zooarchaeology and Taphonomy}

158 159

Over $75 \%$ of dogs with available age indication were classified as adult or older adult. Individuals of indeterminate sex were more numerous than known males. Shoulder height calculations ranged from 350-450 mm, approximating modern mid-sized terriers.

There are no complete axial sequences in the archaeological dataset. However, all vertebrae associated with an individual were examined, regardless of morphology. Abnormal spinous processes were noted in $25 \%$ to $100 \%$ of available vertebrae from individual dog burials. The exception was Apple Creek Burial \#4, a young dog with 13\% variant vertebrae.

Few specimens $(\mathrm{n}=15 ; 8 \%)$ had $\mathrm{pH}$-related surface damage. Mild-to-moderate pitting was found only at Modoc (Dog \#2), Koster (\#2256), and Putney-Apple Creek (Burial \#4). These affected vertebrae reveal concentrations of pitting in areas of strong muscle attachments. Fourteen slightly pitted vertebrae from two individuals had very mild spinous process curving, bowing, or leaning, but pitting was not found with marked deviation of the spinous process. Root etching was found only in Modoc Dog \#6090 (n=6 vertebrae), and was highly localized on each surface area $<1 \mathrm{~cm}^{2}$. Gastric polish was not present on any specimens.

\section{$\underline{3.2 \text { Gross morphology }}$}

We evaluated 191 domestic dog vertebrae from 15 deliberate dog burials $(n=184)$, and isolated vertebrae $(n=7)$. Spinous process deviations were observed in 25/74 (34\%) of cervical; 32/51 (63\%) of thoracic; 47/60 (78\%) of lumbar; and 3/6 (50\%) of sacral vertebrae. Among deviation categories, lateral leaning occurred primarily as a mild change, while lateral curving and bowing each occurred over a range of severity (Table 2). Longitudinal torsion was noted in only three specimens; these were excluded from statistical analysis. Multiple deviations in a single vertebra occurred only twice; both were combined right leaning and right torsion involving cervical vertebrae

A significant association ( $\mathrm{P}=0.032$, Fisher's exact test) was found between deviation category and severity, for leaning and bowing only. No statistically-significant differences were found for right-left distributions (Table 2). Spinous process deviation occurred with vertebral body left- 
185 186

right (lateral) asymmetry in eleven vertebrae, and with articular facet osteophytes in eight vertebrae. Spinous process deviation did not occur with vertebral body spondylosis. The small sizes and distributions of data subsets precluded additional statistical treatment.

Vertebrae from the Alchester, UK Roman site included five thoracic, five lumbar, and one sacrum from the same individual, collectively revealing spinous process deviations (Fig. 3a-c), osteophytes, articular facet asymmetry, and erosion (Table 3). The features were visually identical to those seen from American sites, from the Archaic to recent history. The Alchester circumstances suggest convenient disposal, and cut mark patterns suggest butchery, in contrast to the deliberate burials that we evaluated from North America.

\section{$\underline{3.3 \text { Imaging studies }}$}

\section{$\underline{\text { 3.3.1 Microcomputed tomography of archaeological specimens }}$}

$\mu \mathrm{CT}$ was used to provide highly detailed images of the cortical and trabecular bone of the four archaeological vertebrae that were selected as examples for further evaluation. This procedure illustrates identification of specific diagnoses in some instances and facilitates recognizing that some archaeological diagnoses remain inconclusive despite advanced diagnostics. Specimens 1 and 2 were from the same dog.

Specimen 1, Apple Creek Burial 6 On the basis of full epiphyseal closure and moderate to heavy dental wear, this was an adult dog. A baculum was not recovered. This thoracic vertebra was used as a reference specimen because it showed no spinous process deviation on visual inspection (Fig. 4a). By $\mu \mathrm{CT}$ (Fig. 4b), the trabeculae in the spinous process are uniformly distributed, of similar thickness, and arranged into an organized three-dimensional lattice. The cortex is smooth, uninterrupted, and symmetric.

Specimen 2, Apple Creek Burial 6 A lumbar vertebra showing deviation of the spinous process, same dog as Specimen 1. Gross examination reveals dorsal-ventral fracture of the spinous process, with obvious leaning to the right (Fig. 5a); $\mu \mathrm{CT}$ (Fig. 5b) suggests that force was applied from a posterolateral direction, fracturing the bone, but it is not entirely impossible that a dorsal compression could have occurred. There is no visible healing or remodeling, indicating 
213 that the fracture likely occurred either after death or shortly before. The random pattern of the

214 fractured trabeculae is atypical for living individuals, wherein acutely fractured trabeculae

215 usually align in straight or stellate patterns. A definitive diagnosis is not offered, but the features

216 favor post-mortem damage over pre-mortem injury.

217 Specimen 3, Weaver Site This thoracic vertebra is from a general site assemblage, not a burial;

218 estimates of age and sex were not attempted. Gross examination reveals moderate-severe spinous

219 process lateral curving to the right (Fig. 6a). However, $\mu \mathrm{CT}$ (Fig. 6b) reveals a trabecular pattern

220 that is not encountered in diseased living subjects. Specifically, this trabecular pattern is not

221 recognizable as one that occurs due to trauma, infection, metabolic, or neoplastic conditions in

222 humans or dogs. No normal trabecular structure can be observed along the curved part of the

223 bone; the width of the bone resembles compact bone that has been "melted" and bent. A more

224 normal bone structure can be seen on either end of the feature.

225 Possible influences on this feature could involve soil moisture or chemical composition that

226 slowly dissolved normal bone, with re-deposition by precipitation along lines of force. A second

227 taphonomic possibility could be long-term, highly focal compressive or constrictive forces in-

228 ground. A further possibility is that a fracture occurred postmortem, and new loading patterns

229 were superimposed. Combined pre-mortem and post-mortem effects also cannot be ruled out. No

230 healing process is evident, and a definitive diagnosis cannot be identified, even following $\mu \mathrm{CT}$

231 evaluation.

232 Specimen 4, Apple Creek Burial 3 Ephiphyseal closure is complete and dentition is heavily 233 worn, indicating an older dog. Gross examination reveals significant lateral lumbar spinous

234 process curving with only slightly increased curving of the neck of the spinous process (Fig. 7a).

$235 \mu \mathrm{CT}$ (Fig. 7b) reveals trabeculae that are focally very thickened and aligned in a roughly linear-

236 to-curved pattern, with normal trabeculae at the base of the spinous process, volar to this feature.

237 The cortex is composed of mature-looking compact bone that is thicker than normal on the

238 concave side of the curvature. The appearance suggests mature callus formation and a

239 completely healed-remodeled fracture that occurred during life. The amount of healing suggests

240 that the dog lived at least 3-4 months after the injury. A separate crack along the convex surface

241 likely occurred after death; no tissue response is visible. 


\subsubsection{Computed tomography (CT) of living dogs}

244 Computed tomographic images were included from four living domestic dogs that were

245 presented to the University of Pennsylvania Veterinary Hospital, USA. Medical records provided 246 supporting information that aided each evaluation. In all four cases, while the contour of each 247 spinous process is curved, the ultrastructure of the underlying cortex and trabeculae appear 248 normal, similar to burial Specimen 1.

249 Case 1 (Fig. 8a) German shepherd dog, aged 10 years, with: acute spinal trauma, paraparesis, 250 pneumothorax, T13-L1 subluxation and fracturing, articular facet degenerative joint disease 251 (DJD), degenerative spondylosis, and no prior history of back pain. CT: $2.5 \mathrm{~mm}$ slice thickness, 252 bone algorithm, bone window (WW3750, WL 340), reveals vertebral spinous process curving at 253 T11; cranial-dorsal articular facet margin osteophytes at T10; and right cranial articular facet 254 ventromedial enlargement at T10, with mild encroachment on the vertebral canal.

255 Case 2 (Fig. 8b) Dachshund, aged 8 years, with: back pain; T3-L3 spinal cord myelopathy, 256 paraparesis with deep pain present, compressive herniated disc at L2-3, and no prior history of 257 back pain. CT: $1.25 \mathrm{~mm}$ slice thickness, bone algorithm, bone window (WW 2650, WL 250), 258 reveals vertebral spinous process curving at T11.

259 Case 3 (Fig. 8c) Mixed breed dog, aged 10 years, with: neck pain and otherwise normal neck 260 evaluation, brain-related neurological signs, pulmonary mass, and no prior history of 261 thoracolumbar pain. CT: 0.63mm slice thickness, bone algorithm, bone window (WW 5900, WL 262 235), reveals vertebral spinous process curving at T12.

263 Case 4 (Fig. 8d) Bernese mountain dog, aged 22 months, with urinary incontinence and no prior 264 history of back pain. CT: 2.5mm slice thickness, soft tissue algorithm, bone window (WW 2050, 265 WL 195), reveals vertebral spinous process curving at L3. 
3.4.1 Findings were observationally independent of chronological period, site, and probably culture; further statistical evaluation would be scientifically tenuous in the study circumstances.

3.4.2 Multiplanar reconstruction and volume-rendering of cross-sectional images provided excellent spatial resolution for tomography (Robertson and Thrall, 2011; Viera et al., 2009). The $\mu \mathrm{CT}$ results for two selected ancient vertebrae revealed postmortem fracture (Fig. 5b) and possible slow taphonomic change (Fig. 6b). The healed fracture (Fig. 7) was distinguished readily by $\mu \mathrm{CT}$.

3.4.3 Observations of living dogs included: acute trauma with prior pathology (Case 1); acute intervertebral disc disease and spinous process deviation proximate to localized clinical signs (Case 2); spinous process deviation distant from localized clinical signs (Case 3); and unassociated spinous process deviation (Case 4).

3.4.4 These data confirm that (a) domestic dog vertebral spinous process deviations occur with varying structure, but usually not in combinations; (b) primary or secondary pathology can be represented causally; (c) spinous process deviations can occur before or after death; (d) there is no evident association with sex or age.

\section{Discussion}

The origins of deviated vertebral spinous processes can be complex, potentially resulting from many processes that can operate over time. The differential diagnosis format presented below elaborates four primary etiological groupings. The differentials are not mutually exclusive, nor are they equally testable in archaeological contexts. Multiple interacting causes also must be considered.

We recognize that our data raise a number of questions about considering new studies of potential taphonomic influences; climatic factors post-deposition; broad-scope imaging studies, and relationships to other observed pathology. These ideas, while beyond the scope of the present report, do indicate the need to consider the contributors to thorough differential diagnosis, which we now present. The types of damage that occur during storage (breakage, 
295 296

polish) are clearly distinguishable and unrelated to spinous process deviations, and are not considered further here.

\section{$\underline{4.1 \text { Abnormal spinal morphology }}$}

4.1.1 Bone morphogenesis is diffusely regulated; purely genetic causes of isolated vertebral spinous process anomalies are relatively implausible. The developing mammalian fetus is protected in utero by a thickened gravid uterine wall and by fetal fluids (Evans and Christensen, 1979), but usually is not protected from biochemical damage. Biochemical events that occur in utero and during early life may be diagnostically obscure, but should be considered nonetheless for impact on differential diagnoses.

4.1.2 Hemivertebrae occur primarily in small dogs, especially brachycephalic breeds (Done et al., 1975; White, 2013). Pain, muscle atrophy, abnormal gait, and weakness can be observed in life, but some affected individuals display no overt distress. Regional co-presenting kyphosis or scoliosis may be either secondary or independent events, and a short "screw tail" often is present.

4.1.3 Syringomyelia is a painful condition caused by a large, long, or asymmetrical syrinx in the cervical spinal cord (Rusbridge et al., 2007), and malformation of the caudal occipital bone leads to cerebellar crowding and herniation of brain tissue, obstructing normal flow of cerebrospinal fluid (Rusbridge et al., 2007).

4.1.4 Vertebral malformations may result from unilateral damage causing lateralized loss of paraspinal muscle function, with subsequent atrophy (Van Biervliet et al., 2004) and focal spinal deformity due to unbalanced muscle forces. Or, an upper motor neuron lesion could create lateralized paraspinous muscle dysfunction and result in uniform curving of several vertebral spinous processes.

4.1.5 Mucopolysaccharidosis-I is a lysosomal storage metabolic disease that causes vertebral dysplasia, odontoid hypoplasia of the axis, and intervertebral disk disease. Kypho-scoliosis and spinal cord compression also may be observed (Chiaro et al., 2013).

4.1.6 Scoliosis is a common spinal abnormality among humans, occurring less frequently among dogs. Brachycephalic 'screw-tailed' dogs are predisposed; the cervical and thoracic spine are affected most frequently (Grenn and Lindo, 1969; Sponenberg and Bowling, 1985; Breit and 
323 Kunzel, 2002; Guevar et al., 2014). Association with hydromyelia and syringomyelia has been

324 reported (Child et al., 1986; Takagi et al., 2005).

325 By contrast to domestic dogs, in human scoliosis, the spinous processes of C2-C6 are virtually always bifid, and often bifid at C7. Unilateral hyperplasia at C5, C6, or C7 may be observed (Reinhardt, 1956; Seibert-Daiker, 1975). Thoracic spinous processes usually deviate obliquely from the midline (Freyschmidt et al., 2001). Spinal torsion occurs in the axial plane, and the scoliotic curve in the coronal plane. The spinous processes bend towards the convex side (Wever et al., 1999; Kotwicki and Napiontek, 2008).

4.1.7 Species-independent, non-pathological influences on spinal rotation occur as well. Normal mid-lower (below T5) thoracic spinal rotation to the right has been reported in humans without scoliosis ( Kouwenhoven et al., 2006). The same investigators identified a T1-T13 right rotation in the spine of a normal dog. The course of the descending aorta relates closely to the left aspect of the vertebral column in the thoracic region of both species. Rightward rotational forces during development could associate with the position of the aorta (Kouwenhoven et al., 2006a; 2006b), and any subsequent directional change may be dictated by this pre-existing, non-pathological spinal rotation.

\section{$\underline{4.2 \text { Infection }}$}

4.2.1 Most canine spondylitis occurs as diskospondylitis, thus also involving intervertebral disks (Burkert et al., 2005). Diskospondylitis is thought to result from vascular supply to vertebral end plates, transporting infectious agents. Originating sources include the urinary bladder, endocarditis, periodontal disease, respiratory infections, and wounds or migrating foreign bodies such as grass awns (LeCouteur and Grandy, 2000).

4.2.2 Many offending infectious agents have been associated with canine diskospondylitis. Staphylococci are the most common, but Streptococci, E. coli, and Brucella canis, also are identified with some frequency. Relatively uncommon isolates include Klebsiella, Pseudomonas, Proteus, Actinomyces, Pasteurella, Candida, Mycobacterium species, Aspergillus, and Paecilomyces (LeCouteur and Grandy, 2000). Mixed bacterial infections also are common in animals. The critical diagnostic implication is that genomic testing to identify offending microorganisms must include all possible agents to be credible. 
4.3.1 Carcass burials undergo decomposition phases that simultaneously alter carcass $\mathrm{pH}$ and subject the skeleton to internal and external stresses through differential drying. Production of organic acids associated with decay and putrefaction occurs, along with carcass de-fatting, potentially: (a) causing reduced rigidity of vertebral processes in a low $\mathrm{pH}$ environment; and (b) subjecting these same elements to directional stresses from drying muscles and ligaments (Weigelt, 1989). The clarity provided by imaging or histological studies will support ruling in or out at least some post-depositional causes for spinous process deformity.

4.3.2 Frequencies and interactions among postmortem changes are important aspects of differential diagnosis that must be evaluated as possible causal or influential variables. For instance, pitting of the bone surface in Modoc dog burial \#2 occurs in association with robust muscle attachments along the ventral surface of the spinous process, and with mild deviation of spinous processes. However, no cause-effect relationship is clearly supported. Although surface damage from pitting and root etching is uncommon in our dataset, these factors may impact burials in other contexts.

\section{$\underline{4.4 \text { Life history }}$}

4.4.1 Early-life injury resulting in asymmetrical development of axial muscles can lead to secondary asymmetry of back muscles, vertebral spinous process deviation, and degrees of pain (McGill, 2009).

The origins, attachments, and functional interconnections of oblique abdominal and spinal muscles comprise a 'core strength' that varies highly among individuals (McGill, 2009). Core muscle weakness or pain results in reduced load-bearing strength and spinal instability, with ultimate secondary bone deformity. Diagnostic criteria include deviation of spinous processes at gross observation, with "normal" trabecular microstructure.

4.4.2 Analysis of skeletal indicators for work-related behaviors (running, carrying loads, grinding corn) is common in bioarchaeology (Larsen, 1987). Long-term, low-level stresses on the skeleton affect bone shape through asymmetrical development of muscle attachments and subsequent remodeling processes. 
4.4.3 Trauma causing fracture of a spinous process can result from mistreatment or carrying loads that are too heavy at a young age (prior to development of supporting musculature and bone strength) (Snyder, 1995; Warren, 2000; Darwent and Gililand, 2001; Walker et al., 2005). Diagnostic criteria include formation of a callus-type response (healing bone) and associated reorganization of trabeculae.

\section{Conclusion}

It is our view that pathology studies of ancient animals can provide valuable information with respect to animal health and the nature of the human-animal bond, although differential diagnosis must be thorough if interpretations are to be accurate. While definitive diagnosis may not be possible in many instances, imaging studies can produce a narrowed field of possibilities that are most plausible in a given circumstance. In the case of domestic dog vertebral spinous process deviations, it is evident that earlier causal explanations would need to be re-evaluated in differential diagnosis formats, or discarded.

We have indicated a range of possible explanations that could account for deviations of vertebral spinous processes in dogs. We have provided both specific imaging examples and a discussion of how investigators can use an orderly and detailed process to approach differential diagnosis. Comparative study of vertebrae from a geographically distant site yielded similar observations, indicating that our North America observations are not unique geographically, but also demonstrating that new studies in broader scope are desirable.

Macroscopic and radiographic analyses, supplemented by computed and microcomputed tomography, along with awareness of rigorous differential diagnosis, are requirements for confident archaeological interpretations. Our report did not include histology, but increasing use of histological methods will be useful in future diagnostic processes as well. Another critical factor is to correctly separate taphonomic from biological influences; our observations suggest that this is not uniformly possible, leading thus to a realization that some differential diagnoses will proceed only as far as a narrowed list of alternatives.

\section{Supplemental Materials}


Computed tomography imagery of the four archaeological specimens will be provided through an online data repository upon acceptance.

\section{Acknowledgements}

This study benefitted greatly from discussions with Ken Farnsworth, Mike Wiant, and Dee Ann Watt. The Illinois State Museum Research and Collections Center provided access to the study materials.

\section{References}

Andrews, P., 1990. Owls, Caves and Fossils: Predation, Preservation and Accumulation of Small Mammals Bones in Caves. University of Chicago Press, Chicago.

Baker, J.R., Brothwell, D.R., 1980. Animal diseases in archaeology. Academic Press, London.

Bartosiewicz, L., Gal, E., 2013. Shuffling Nags, Lame Ducks: The Archaeology of Animal Disease. Oxbow Books, Oxford, UK.

Breit, S., Kunzel, W., 2002. Shape and Orientation of Articular Facets of Cervical Vertebrae (C3-C7) in Dogs Denoting Axial Rotational Ability: An Osteological Study. Eur. J. Morphol. 40, 43-51. doi:10.1076/ejom.40.1.43.13953

Brothwell, D.R., Gill-Robinson, H., 2001. Taphonomic and Forensic Aspects of Bog Bodies, in: Haglund, W., Sorg, M.H. (Eds.), Advances in Forensic Taphonomy: Method, Theory, and Archaeological Perspectives. CRC Press, New York, pp. 119-131.

Burkert, B.A., Kerwin, S.C., Hosgood, G.L., Pechman, R.D., Fontenelle, J.P., 2005. Signalment and clinical features of diskospondylitis in dogs: 513 cases (1980-2001). J. Am. Vet. Med. Assoc. 227, 268-275. doi:10.2460/javma.2005.227.268

Chhem, R., Brothwell, D.R., 2008. Paleoradiology: Imaging mummies and fossils, Paleoradiology: Imaging Mummies and Fossils. Springer Berlin Heidelberg.

Chiaro, J.A., Baron, M.D., Del Alcazar, C.M., O’Donnell, P., Shore, E.M., Elliott, D.M., Ponder, K.P., Haskins, M.E., Smith, L.J., 2013. Postnatal progression of bone disease in the cervical spines of mucopolysaccharidosis I dogs. Bone 55, 78-83. doi:10.1016/j.bone.2013.03.014

Child, G., Higgins, R.J., Cuddon, P.A., 1986. Acquired scoliosis associated with hydromyelia and syringomyelia in two dogs. J. Am. Vet. Med. Assoc. 189, 909-912.

Darwent, C.M., Gililand, J.E., 2001. Osteological Analysis of Domestic Dogs from Burials in Southern Missouri. Missouri Archaeol. 62, 149-169.

Davies, J., Fabis, M., Mainland, I., Richards, M., Thomas, R., 2005. Diet and health in past 
animal populations : current research and future directions, in: Proceedings of the 9th ICAZ Conference, Durham. Oxbow Books, Oxford, UK.

Done, S., Drew, R., Robins, G., Lane, J., 1975. Hemivertebra in the dog: clinical and pathological observations. Vet. Rec. 96, 313-317. doi:10.1136/vr.96.14.313

Evans, H.E., Christensen, G.C., 1979. Miller's anatomy of the dog, 2nd ed. WB Saunders, Philadelphia.

Fowler, M.L., 1959. Modoc Rock Shelter: An Early Archaic Site in Southern Illinois. Am. Antiq. $24,257-270$.

Freyschmidt, J., Brossmann, J., Wiens, J., Sternberg, A., 2001. Borderlands of normal and early pathological findings in skeletal radiography, 5th ed, George Thieme Verlag.

Gill-King, H., 1997. Chemical and ultrastructural aspects of decomposition, in: Haglund, W.D., Sorg, M.H. (Eds.), Forensic Taphonomy: The Postmortem Fate of Human Remains. CRC Press, New York, pp. 93-108.

Grenn, H.H., Lindo, D.E., 1969. Hemivertebrae with severe kypho-scoliosis and accompanying deformities in a dog. Can. Vet. J. 10, 214-6.

Griffin, J., Morse, D., 1961. The Short-Nosed God from the Emmons Site, Illinois. Am. Antiq. $26,560-563$.

Guevar, J., Penderis, J., Faller, K., Yeamans, C., Stalin, C., Gutierrez-Quintana, R., 2014. Computer-assisted radiographic calculation of spinal curvature in brachycephalic "screwtailed" dog breeds with congenital thoracic vertebral malformations: reliability and clinical evaluation. PLoS One 9, e106957. doi:10.1371/journal.pone.0106957

Haglund, W., Sorg, M.H., 1997. Forensic taphonomy : the postmortem fate of human remains. CRC Press, Boca Raton.

Harcourt, R., 1974. The dog in prehistoric and early historic Britain. J. Archaeol. Sci. 1, 151175.

Jalalzadeh, H., Giannakopoulos, G.F., Berger, F.H., Fronczek, J., van de Goot, F.R., Reijnders, U.J., Zuidema, W.P., 2015. Post-mortem imaging compared with autopsy in trauma victims - A systematic review. Forensic Sci. Int. 257, 29-48.

Johnson, E., Gutierrez, M., Politis, M., Martinez, G., Hartwell, T., 1997. Holocene Taphonomy at Paso Otero 1 on the Eastern Pampas of Argentina, in: Hannus, L.A., Rossum, L., Winham, R.P. (Eds.), Proceedings of the 1993 Bone Modification Conference, Hot Springs, South Dakota. Archeology Laboratory, Augustana College: Occasional Publication No. 1, Sioux Falls, SD, pp. 105-121.

Kotwicki, T., Napiontek, M., 2008. Intravertebral deformation in idiopathic scoliosis: a transverse plane computer tomographic study. J. Pediatr. Orthop. 28, 225-9. doi:10.1097/BPO.0b013e3181647c4a

Kouwenhoven, J.-W.M., Vincken, K.L., Bartels, L.W., Castelein, R.M., 2006. Analysis of preexistent vertebral rotation in the normal spine. Spine (Phila. Pa. 1976). 31, 1467-1472.

Kouwenhoven, J.-W.M., Vincken, K.L., Bartels, L.W., Meij, B.P., Oner, F.C., Castelein, R.M., 
2006. Analysis of preexistent vertebral rotation in the normal quadruped spine. Spine (Phila. Pa. 1976). 31, E754-8. doi:10.1097/01.brs.0000240209.85498.01

Larsen, C.S., 1987. Bioarchaeological interpretation of subsistence economy and behavior from human skeletal remains. Adv. Archaeolological Method Theory 10, 27-56.

Larson, G., Karlsson, E.K., Perri, A., Webster, M.T., Ho, S.Y.W., Peters, J., Stahl, P.W., Piper, P.J., Lingass, F., Fredholm, M., Comstock, K.E., Modiano, J.F., Schelling, C., Agoulnik, A.I., Leegwater, P.A., Dobney, K., Vigne, J.-D., Vila, C., Andersson, L., Lindblad-Toh, K., 2012. Rethinking dog domestication by integrating genetics, archaeology, and biogeography. PNAS 109, 8878-8883.

Lawler, D.F., Reetz, J.A., Sackman, J.E., Evans, R.H., Widga, C., 2015. Suspected hypertrophic osteopathy in an ancient canid: Differential diagnosis of possible etiologies. Int. J. Paleopathol. 9, 52-58. doi:10.1016/j.ijpp.2015.02.001

LeCouteur, R.A., Grandy, J.L., 2000. Diseases of the Spinal Cord, in: Ettinger, S.J., Feldman, E.C. (Eds.), Textbook of Veterinary Medicine. Saunders, Philadelphia, pp. 608-657.

Lyman, R.L., 1994. Vertebrate Taphonomy. Cambridge University Press.

Lynnerup, N., 2010. Medical imaging of mummies and bog bodies - a mini-review. Gerontology $56,441-448$.

McGill, S., 2009. Ultimate back fitness and performance. Backfit Pro, Inc., Waterloo, ON, Canada.

McMillan, R.B., 1976. Rodgers Shelter: A Record of Cultural and Environmental Change, in: McMillan, R.B., Wood, W.R. (Eds.), Prehistoric Man and His Environments: A Case Study in the Ozark Highland. Academic Press, New York, pp. 111-122.

Miklíková, Z., Thomas, R., 2008. Current research in animal palaeopathology. BAR International Series 1814., Oxford, UK.

Miklósi, A., 2007. Dog behaviour, evolution, and cognition. Oxford University Press, Oxford.

Miller, E., Ragsdale, B., Ortner, D.J., 1996. Accuracy in Dry Bone Diagnosis : a Comment on Palaeopathological Methods. Int. J. Osteoarchaeol. 6, 221-229. doi:10.1002/(SICI)1099

Moodie, R.L., 1923. Paleopathology: An Introduction To the Study of Ancient Evidence for Disease. University of Illinois Press.

Morey, D.F., 2010. Dogs: Domestication and the development of a social bond. Cambridge University Press. doi:10.1017/CBO9780511778360

Morey, D.F., 2006. Burying key evidence: the social bond between dogs and people. J. Archaeol. Sci. 33, 158-175. doi:10.1016/j.jas.2005.07.009

Morey, D.F., Wiant, M.D., 1992. Early Holocene Domestic Dog Burials From the North American Midwest. Curr. Anthropol. 33, 224. doi:10.1086/204059

Morlan, R., 1984. Toward the Definition of Criteria for the Recognition of Artificial Bone Alterations. Quat. Res. 22, 160-171.

Newton, C.D., Nunamaker, D.M., 1985. Textbook of Small Animal Orthopaedics. J. B. 

Lippincott Company.

Nowak, R.M., Mech, L.D., Gipson, P.S., Ballard, W.B., 2000. Accuracy and precision of estimating age of gray wolves by tooth wear. J. Wildl. Manage. 64, 752-758.

Ortner, D.J., 2003. Identification of pathological conditions in human skeletal remains. Academic Press.

Parmalee, P.W., Paloumpis, A.A., Wilson, N., 1972. Animals Utilized by Woodland Peoples Occupying the Apple Creek Site, Illinois. Illinois State Museum, Reports Investig. 23.

Reinhardt, K., 1956. Eine ungewöhnliche Anomalie an den Dornfortsätzen des 5, 6, und 7. Halswirbels Fortschr Rontgenstr 85, 253-255.

Robertson, I., Thrall, D.E., 2011. Imaging dogs with suspected disc herniation: pros and cons of myelography, computed tomography, and magnetic resonance. Vet. Radiol. ultrasound 52, S81-84. doi:10.1111/j.1740-8261.2010.01788.x

Rusbridge, C., Carruthers, H., Dubé, M.-P., Holmes, M., Jeffery, N.D., 2007. Syringomyelia in cavalier King Charles spaniels: the relationship between syrinx dimensions and pain. J. Small Anim. Pract. 48, 432-6. doi:10.1111/j.1748-5827.2007.00344.x

Seibert-Daiker, F., 1975. Über eine halbseitige Dornfortsatzhyperplasie des 5. Halswirbels Fortschr Rontgenstr 122, 366-377.

Snyder, L.M., 1995. Assessing the role of the domestic dog as a Native American food resource in the Middle Missouri Subarea A.D. 1000-1840 (Book, 1995) [WorldCat.org]. University of Tennessee.

Sponenberg, D.P., Bowling, A.T., 1985. Heritable syndrome of skeletal defects in a family of Australian shepherd dogs. J. Hered. 76, 393-395.

Takagi, S., Kadosawa, T., Ohsaki, T., Hoshino, Y., Okumura, M., Fujinaga, T., 2005. Hindbrain decompression in a dog with scoliosis associated with syringomyelia. J. Am. Vet. Med. Assoc. 226, 1359-1363. doi:10.2460/javma.2005.226.1359

Tourigny, E., Thomas, R., Guiry, E., Earp, R., Allen, A., Rothenberger, J.D., Lawler, D., Nussbaumer, M., 2015. An Osteobiography of a 19th-Century Dog from Toronto, Canada. Int. J. Osteoarchaeol. DOI: 10.1002/oa.2483

Upex, B., Dobney, K., 2012. More Than Just Mad Cows: Exploring Human-Animal Relationships through Animal Paleopathology, in: Grauer, A.L. (Ed.), A Companion to Paleopathology. Blackwell Publishers, pp. 191-213. doi:10.1002/9781444345940.ch11

Van Biervliet, J., DeLahunta, A., Ennulat, D., Oglesbee, M., Summer, B., 2004. Acquired cervical sclerosis in six horses associated with dorsal grey column chronic myelitis. Equine Vet. Journal2 36, 86-92.

Viera, R.L.R., Arora, R., Scheweitzer, M.E., 2009. Radiologic Imaging of Spinal Deformities, in: Errico, T.J., Lonner, B.S., Moulton, A.W. (Eds.), Surgical Management of Spinal Deformities. Saunders Elsevier, Philadelphia, pp. 45-60.

Walker, R.B., Morey, D.F., Relethford, J.H., 2005. Early and Mid-Holocene Dogs in Southeastern North America: examples from Dust Cave. Southeast. Archaeol. 24, 83-92. 
575

576

577

578

579

580

581

582

583

584

585
Ware, C.S., 2006. Disease, Skeletal Injury and Trauma as Possible Behavioral Modifiers in the Fossil Dire Wolf Canis dirus (Canidae: Carnivora) from Rancho La Brea, California. Union Institute \& University, Cincinnati, $\mathrm{OH}$.

Warren, D.M., 2004. Skeletal Biology and Paleopathology of Domestic Dogs from Prehistoric Alabama, Illinois, Kentucky and Tennessee. University of Indiana.

Warren, D.M., 2000. Paleopathology of Archaic Dogs from the North American Southeast, in: Crockford, Susan, J. (Ed.), Dogs Through Time An Archaeological Perspective. BAR International Series 2000, pp. 93-104.

Weigelt, J., 1989. Recent vertebrate carcasses and their paleobiological implications. University of Chicago Press, Chicago.

Wever, D.J., Veldhuizen, A.G., Klein, J.P., Webb, P.J., Nijenbanning, G., Cool, J.C., v. Horn, J.R., 1999. A biomechanical analysis of the vertebral and rib deformities in structural scoliosis. Eur. Spine J. 8, 252-260. doi:10.1007/s005860050169

White, D., 2013. Screening for hemivertebra in pugs. Vet. Rec. 173, 24. doi:10.1136/vr.f4289

Wray, D.E., MacNeish, R.S., 1961. The Hopewellian and Weaver Occupations of the Weaver Site: Fulton County, Illlinois, Scientific Papers 7. Illinois State Museum. 
Figure Legends

587

588

589

590

591

592

593

594

595

596

597

598

599

600

601

602

603

604

605

606

607

608

609

610

611

612

613

614

615

616

617

618

Fig. 1. Map of sites included in this study.

Fig. 2a. Koster, Feature 2256. Cervical: Spinous process near normal, but with very mild lean to left (white arrow); mild periarticular rim of right anterior articular facet (grey arrow)

Fig. 2b. Apple Creek, Burial 6. Lumbar: Spinous process severe right curving (white arrow); very mild asymmetry anterior articular facets (grey arrows)

Fig. 2c. McDonough Lake. Lumbar: Spinous process bowlike deformity (short white arrows) with visible crack anterior margin; asymmetry and proliferation on mamillary processes (long white arrows); small osteophyte cranioventral margin (short grey arrow)

Fig. 2d. Koster, Feature 2256. Thoracic: Mild right torsion spinous process (grey indicator lines)

Fig. Alchester, England. 3a. Lumbar: Spinous process left bow (white arrow), with mild right torsion (short grey arrows)

Fig. 3b. Alchester, England. Thoracic: Spinous process mild right curving (larger white arrow); anterior articular facets rough margins (short white arrows); anterior \& posterior end plates severe ventral \& lateral osteophytes (short grey arrows)

Fig. 3c. Alchester, England. Thoracic: Spinous process mild right curving (long white arrow); posterior articular facet asymmetry; mild transverse process osteophytes; anterior articular facets rough margins and mild asymmetry (short white arrows)

Fig. 4a. Apple Creek, Burial 6, Specimen 1. Thoracic: Normal spinous process.

Fig. 4b. Apple Creek, Burial 6, Specimen 1. Thoracic $\mu$ CT: Spinous process demonstrates normal cortex and trabeculae.

Fig. 5a. Apple Creek, Burial 6, Specimen 2. Lumbar: Spinous process visible cracking and moderate curving to the right (long grey arrow); dorsal arch asymmetry (short grey arrows); small ventromedial and ventrolateral osteophytes (white arrows)

Fig. 5b. Apple Creek, Burial 6, Specimen 2.Lumbar $\mu \mathrm{CT}$ : Fracturing, no healing or remodeling (short grey arrow); irregular trabecular pattern (long white arrows); probable post-mortem trauma

Fig. 6a. Weaver Site, Specimen 3. Thoracic: Spinous process severe right curving (arrow)

Fig. 6b. Weaver Site, Specimen 3. Thoracic $\mu \mathrm{CT}$ : 'Blurring' of detail consistent with postmortem slow taphonomic mineralizing change possibly resulting from compressive or constrictive forces in situ (arrows), but an open diagnosis 
619 Fig. 7a. Apple Creek, Burial 3, Specimen 4. Lumbar: Spinous process severe right curving 620 (arrow)

621 Fig. 7b. Apple Creek, Burial 3, Specimen 4. Lumbar $\mu$ CT: Callus formation consistent with 622 fracture during life; healing and remodeling (white arrows); artifact cracking postmortem (short 623 grey arrow)

624 Fig. 8a. German Shepard (modern), age 10 yr. Thoracic CT: Spinous process right curving 625 (medium arrow); osteophytes dorsal margins of cranial articular facets (short arrows); focal 626 enlargement ventromedial right cranial articular facet (long arrow)

627 Fig. 8b. Dachshund (modern), age 8 yr. Thoracic CT: Spinous process right curving (white 628 arrow)

629 Fig. 8c. Mixed Breed (modern), age 10. Thoracic CT: Spinous process right curving (white 630 arrow)

631 Fig. 8d. Bernese Mountain Dog (modern), age 22 months. Lumbar CT: Spinous process right 632 curving, lumbar vertebra (white arrow)

633 
Table 1. Age, Sex, body-size, and gross pathology of dog remains included in this study.

\begin{tabular}{|c|c|c|c|c|c|c|c|c|c|}
\hline Period & Site & $\begin{array}{l}\text { Age } \\
\text { (cal BP) }\end{array}$ & ID & Age & $\begin{array}{l}\text { Shoulder } \\
\mathrm{Ht}(\mathrm{mm}) \\
\end{array}$ & Sex & $\begin{array}{l}\text { Tot } \\
1\end{array}$ & $\mathrm{~N}^{2}$ & $\mathrm{Ab}$ \\
\hline \multirow[t]{6}{*}{ Archaic } & \multirow{2}{*}{$\begin{array}{l}\text { Modoc Shelter, Randolph Co., } \\
\text { IL }\end{array}$} & $8560-8200$ & Burial 2 & Adult, old & 453.66 & Male & 16 & 7 & 9 \\
\hline & & $5720-5330$ & 6090 & Adult & 385.06 & Female/Indeterminate & 7 & 3 & 4 \\
\hline & Stilwell, Calhoun Co., IL & $\begin{array}{l}10,190- \\
9630\end{array}$ & Burial & Adult, old & $450.33(\mathrm{rd})$ & Female/Indeterminate & 8 & 2 & 6 \\
\hline & \multirow[t]{3}{*}{ Koster, Greene Co., IL } & \multirow{3}{*}{$\begin{array}{l}10,130- \\
9680\end{array}$} & 2256 & Adult & 446.8 & Female/Indeterminate & 18 & 7 & 11 \\
\hline & & & 222 & Adult & 388.49 & Female/Indeterminate & 7 & 4 & 3 \\
\hline & & & 2407 & Adult & 453.66 & Male & 16 & 5 & 11 \\
\hline \multirow[t]{3}{*}{ Hopewell } & Apple Creek, Greene Co., IL & $2000-1600$ & Burial 6 & Adult, old & 371.34 & Female/Indeterminate & 18 & 7 & 11 \\
\hline & Raker Mound, Fulton Co., IL & $2000-1600$ & Assemblage & & & & 11 & 0 & 11 \\
\hline & Weaver Village, Fulton Co., IL & $2000-1600$ & Assemblage & & & & 7 & 4 & 3 \\
\hline \multirow[t]{7}{*}{ Late Woodland } & \multirow[t]{7}{*}{ Apple Creek, Greene Co., IL } & \multirow[t]{7}{*}{$1550-900$} & Burial 2 & $\begin{array}{l}6 \mathrm{mo} \text { to } 1 \\
\text { year }\end{array}$ & & Female/Indeterminate & 7 & 3 & 4 \\
\hline & & & Burial 4 & $\begin{array}{l}6 \mathrm{mo} \text { to } 1 \\
\text { year }\end{array}$ & 350.76 & Female/Indeterminate & 15 & 13 & 2 \\
\hline & & & Burial 1 & Adult & 415.93 & Female/Indeterminate & 4 & 3 & 1 \\
\hline & & & Burial 3 & Adult, old & $\begin{array}{l}429.78 \\
(\mathrm{fm})\end{array}$ & Female/Indeterminate & 10 & 2 & 8 \\
\hline & & & Burial 5 & Adult, old & 415.93 & Female/Indeterminate & 9 & 6 & 3 \\
\hline & & & Burial 7 & & & & 6 & 4 & 2 \\
\hline & & & Assemblage & & & & 7 & 4 & 3 \\
\hline \multirow[t]{2}{*}{$\begin{array}{l}\text { Mid- } \\
\text { Mississippian }\end{array}$} & \multirow[t]{2}{*}{ Emmons, Fulton Co., IL } & \multirow[t]{2}{*}{$600-540$} & $\begin{array}{l}\text { Hillside } \\
\text { burial }\end{array}$ & Adult & 433.08 & Female/Indeterminate & 12 & 4 & 8 \\
\hline & & & Burial 3 & Adult & 419.36 & Female/Indeterminate & 3 & 1 & 2 \\
\hline Mississippian & McDonough Lake & $900-560$ & Assemblage & & & & 8 & 4 & 4 \\
\hline Late Prehistoric & $\begin{array}{l}\text { Rodgers Shelter, Benton Co., } \\
\text { MO }\end{array}$ & $850-200$ & Assemblage & & & & 2 & 1 & 1 \\
\hline
\end{tabular}

${ }^{1}$ Total vertebrae from individual or assemblage

${ }^{2}$ Number of normal vertebrae

${ }^{3}$ Number of abnormal vertebrae 
636 Table 2. Vertebral Spinous Process Deviations in Archaeological Domestic Dogs [n (\%)]

\begin{tabular}{|l|l|l|l|l|}
\hline & Lean & Curve & Bow & Torsion \\
\hline Degree & & & & \\
\hline Mild & $24(80 \%)^{\mathrm{ab}}$ & $27(45 \%)$ & $9(56 \%)$ & $3(100 \%)$ \\
\hline Moderate & $3(10 \%)$ & $14(23 \%)$ & $4(25 \%)$ & \\
\hline Severe & $3(10 \%)$ & $19(32 \%)$ & $3(19 \%)$ & \\
\hline & & & & \\
\hline Direction & & & & \\
\hline Right & $15(50 \%)$ & $34(57 \%)$ & $7(44 \%)$ & \\
\hline Left & $15(50 \%$ & $26(43 \%)$ & $9(56 \%)$ & \\
\hline
\end{tabular}

637

${ }^{\text {a }}$ Percents refer to column only

$638{ }^{\mathrm{b}}$ Significant difference morphology $\mathrm{x}$ severity, $\mathrm{P}=0.032$ 
641 Table 3. Observations from Roman Domestic Dog Vertebrae, Alceister Site, England

642 Thoracic 4: Anterior articular facets mild asymmetry \& rough margins; transverse process 643 osteophytes.

644 Thoracic 5: Anterior \& posterior end plate osteophytes, posterior osteophytes are severe; anterior 645 articular facets rough margins \& mild asymmetry; transverse process osteophytes.

646 Thoracic 7: Spinous process mild right curve; posterior articular facet asymmetry; mild 647 transverse process osteophytes; anterior articular facets rough margins \& mild asymmetry (Fig. 648 2c).

649

650 Thoracic 9: Anterior \& posterior end plate osteophytes; posterior end plate fine pitting and oval 651 focus of eburnation; anterior articular facet rough margins \& mild asymmetry; anterior \& 652 posterior end plate osteophytes not visible in photograph.

653 Thoracic 13: Spinous process mild right bow; anterior articular facets rough margins; anterior \& 654 poster end plates severe ventral \& lateral osteophytes (Fig. 2b).

655 Lumbar 3: Spinous process mild right curve; anterior end plate severe lateral \& ventral 656 osteophytes.

657 Lumbar 4: Anterior \& posterior articular facets mild asymmetry and mild anterior osteophytes; 658 lateral and ventral anterior end plate mild osteophytes.

659 Lumbar 5: Spinous process bow to left, with mild right torsion; posterior articular facets 660 asymmetry (Fig. 2a).

661 Lumbar 6: Spinous process curve left.

662 Lumbar 7: Spinous process broken (post-mortem); posterior end plate ventral \& lateral 663 osteophytes.

664 Sacrum: Anterior end plate ventral \& lateral osteophytes. 